\title{
Astroglial connexin43 contributes to neuronal suffering in a mouse model of Alzheimer's disease
}

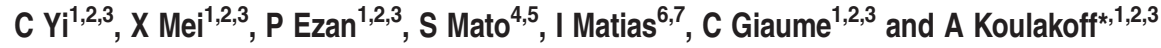

In Alzheimer's disease (AD), astrocyte properties are modified but their involvement in this pathology is only beginning to be appreciated. The expression of connexins, proteins forming gap junction channels and hemichannels, is increased in astrocytes contacting amyloid plaques in brains of AD patients and APP/PS1 mice. The consequences on their channel functions was investigated in a murine model of familial $A D$, the $A P P_{\text {swe }} / P 1_{d E 9}$ mice. Whereas gap junctional communication was not affected, we revealed that hemichannels were activated in astrocytes of acute hippocampal slices containing $A \beta$ plaques. Such hemichannel activity was detected in all astrocytes, whatever their distance from amyloid plaques, but with an enhanced activity in the reactive astrocytes contacting amyloid plaques. Connexin43 was the main hemichannel contributor, however, a minor pannexin1 component was also identified in the subpopulation of reactive astrocytes in direct contact with plaques. Distinct regulatory pathways are involved in connexin and pannexin hemichannel activation. Inflammation triggered pannexin hemichannel activity, whereas connexin 43 hemichannels were activated by the increase in resting calcium level of astrocytes. Importantly, hemichannel activation led to the release of ATP and glutamate that contributed to maintain a high calcium level in astrocytes placing them in the center of a vicious circle. The astroglial targeted connexin43 gene knocking-out in $A P P_{\text {swe }} / P S 1_{\mathrm{dEg}}$ mice allowed to diminish gliotransmitter release and to alleviate neuronal damages, reducing oxidative stress and neuritic dystrophies in hippocampal neurons associated to plaques. Altogether, these data highlight the importance of astroglial hemichannels in AD and suggest that blocking astroglial hemichannel activity in astrocytes could represent an alternative therapeutic strategy in AD.

Cell Death and Differentiation (2016) 23, 1691-1701; doi:10.1038/cdd.2016.63; published online 8 July 2016

In Alzheimer's disease (AD), the histopathological hallmarks are amyloid- $\beta(\mathrm{A} \beta)$ deposition, neurofibrillary tangles, progressive neuronal suffering and synaptic loss in selective brain areas. ${ }^{1}$ An invariant feature is the reactive gliosis associated to $A \beta$ plaques ${ }^{1}$ where activated microglia are recruited and astrocytes exhibit a morphofunctional remodeling modifying their interactions with neurons. ${ }^{2}$ Indeed, glial cells are increasingly considered as important players in neuropathological processes challenging the neurocentric view of brain diseases, ${ }^{3-6}$ but how glial changes contribute to the pathological processes requires further investigation.

In human AD brain ${ }^{7,8}$ and murine models of familial AD (FAD), ${ }^{9}$ we previously showed that the expression of astroglial connexins (Cxs), $\mathrm{Cx} 30$ and $\mathrm{Cx} 43$, is increased in the reactive astrocytes surrounding plaques. Cxs are transmembrane proteins forming hemichannels (HCs) which, by docking between adjacent cells, constitute intercellular gap junction channels. ${ }^{10}$ The latter underly the astroglial network organization that enables small molecule diffusion to distant cells and contributes to $\mathrm{K}^{+}$and glutamate buffering and metabolic trafficking. ${ }^{11}$ Interestingly, in two FAD models, gap junctional communication was enhanced or unchanged compared with control mice, ${ }^{12,13}$ suggesting that the presence of $A \beta$ has no major impact on signal diffusion within the astroglial network. Cxs can also work as HCs allowing exchanges between the cytoplasm and the extracellular medium. ${ }^{14}$ Increasing evidence indicates that HCs formed by Cxs or by another family of proteins, the pannexins $(\operatorname{Panx})^{15}$ have important roles in pathological situations. ${ }^{16-18} \mathrm{HC}$ openings can be triggered in astrocytes after $A \beta$ treatment or in inflammatory situations, ${ }^{19-22}$ both occurring in AD. Such activation leads to ATP and glutamate release with neurotoxic effects. ${ }^{21}$ Interestingly, Cx43 HCs were proposed as a source of ATP release in a FAD model. ${ }^{23}$ Therefore, we asked whether Cx channel functions, noticeably $\mathrm{HC}$ function, are impacted in astrocytes of Alzheimer's mice and what are the consequences on neurons.

We have used a FAD model, the $A P P_{\text {swe }} / P S 1_{d E 9}$ mice (named APP/PS1), ${ }^{24}$ in which we found that gap junctional

\footnotetext{
${ }^{1}$ Center for Interdisciplinary Research in Biology (CIRB), Collège de France, 75005 Paris, France; ${ }^{2}$ Centre National de la Recherche Scientifique Unité Mixte de Recherche 7241, 75005 Paris, France; ${ }^{3}$ Institut National de la Santé et de la Recherche Médicale U1050, 75005 Paris, France; ${ }^{4}$ Achucarro Basque Center for Neuroscience, Centro de Investigación Biomédica en Red en Enfermedades Neurodegenerativas (CIBERNED), Leioa, Spain; ${ }^{5}$ Departamento de Neurociencias, Universidad del Pais Vasco, Leioa, Spain; ${ }^{6}$ Institut National de la Santé et de la Recherche Médicale U1215, Neurocentre Magendie, 33077 Bordeaux, France and ${ }^{7}$ Université de Bordeaux, 33077 Bordeaux, France

*Corresponding author: A Koulakoff, Center for Interdisciplinary Research in Biology, Collège de France, 11 place Marcelin Berthelot, 75005 Paris, France. Tel: 331442712575; Fax: 33144271268; E-mail: annette.koulakoff@college-de-france.fr

Abbreviations: $\mathrm{A} \beta$, amyloid- $\beta$; AD, Alzheimer's disease; APP, amyloid precursor protein; ATP, adenosine triphosphate; CBX, carbenoxolone; Cx, connexin; EtBr, ethidium bromide; FAD, familial Alzheimer's disease; FRAP, fluorescence recovery after photobleaching; GABA, gamma-aminobutyric acid; GFAP, glial fibrillary acidic protein; HC, hemichannel; IL, interleukin; IP3, inositol triphosphate; KO, knock-out; mGluR, metabotropic glutamate receptor; P2, purinergic type2; PanX, pannexin; PKC, protein kinase C; PS1, presenilin-1; RTN3, reticulon 3; RIDN, reticulon 3 immunoreactive dystrophic neurite; SAPP $\alpha$, soluble amyloid precursor protein alpha; SR101, sulforhodamine-101; TGF $\beta$, transforming growth factor beta; TNF $\alpha$, tumor necrosis factor $\alpha$; WT, wild-type

Received 21.3.16; revised 19.5.16; accepted 25.5.16; Edited by N Bazan; published online 08.7.2016
} 

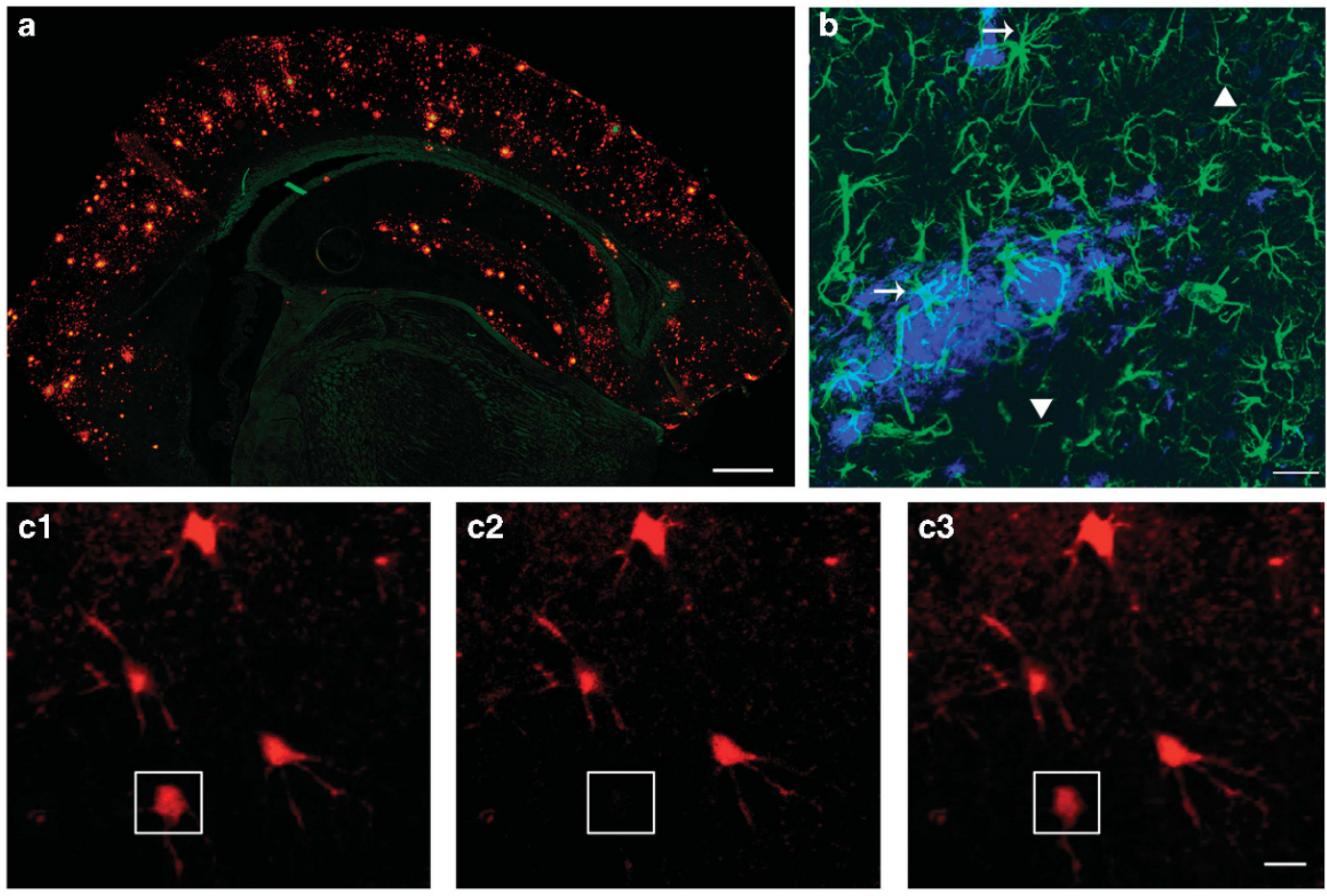

d

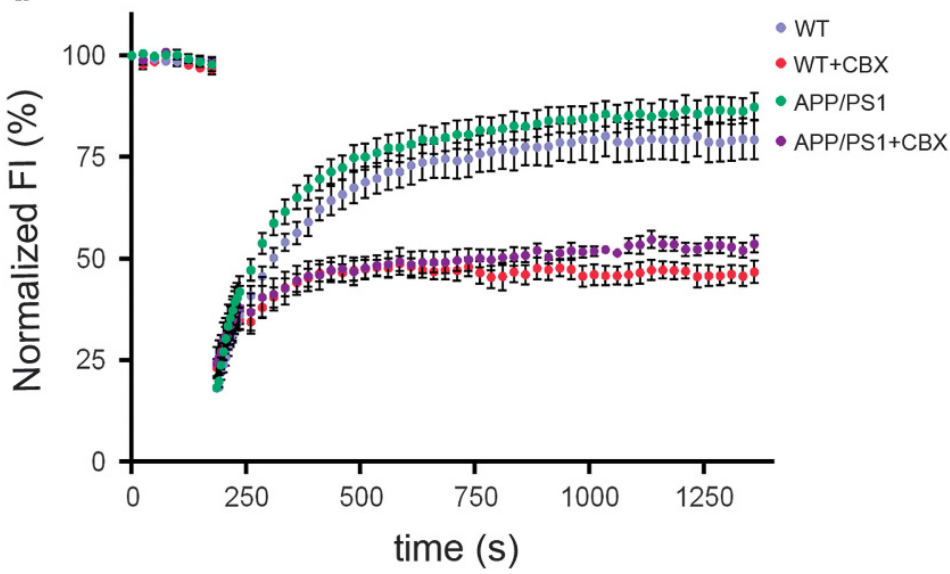

\section{e}

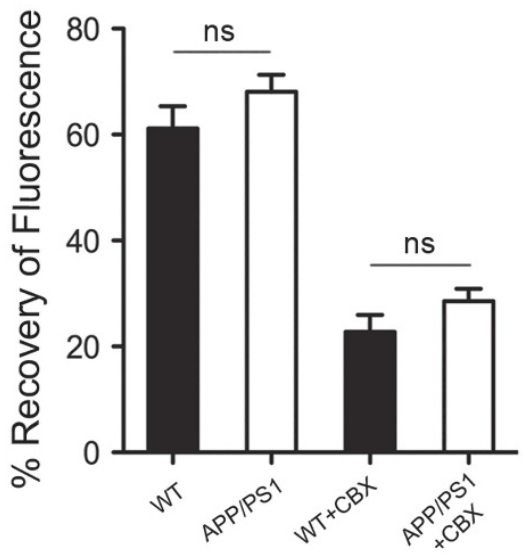

Figure 1 Maintained gap junctional communication in astrocytes of old APP/PS1 mice. (a) Distribution of A $\beta$ plaques in brain sections of 9-month-old APP/PS1 mice, stained for A $\beta$ (red) and thioflavine (green); scale bar, $1000 \mu \mathrm{m}$. (b) Double immunostaining for GFAP (green) and A $\beta$ (blue) of a hippocampal section from 9-month-old APP/PS1 mouse showing the reactive phenotype of astrocytes contacting plaques (white arrow) compared with astrocytes far from plaques (white triangle); scale bar, $30 \mu \mathrm{m}$. (c) The FRAP technique was used to quantify gap junction function. Images of astrocytes loaded with the gap junction-permeable tracer SR101 before bleaching (c1), immediately after bleaching in the white rectangle (c2) and 20 min after laser bleach (c3); scale bar, $10 \mu \mathrm{m}$. (d and e) Analysis of FRAP in the astrocytes of 9-month-old WTand APP/PS1 mice with or without CBX. (d) Time-lapse percentage of fluorescence intensity (FI) normalized with $\mathrm{F}_{0}$. (e) Quantification of fluorescence recovery percentage showing no significant differences between the two genotypes (ns, not significant; unpaired Student's $t$-test; mean \pm S.E.M., WT $n=8 ;$ APP/PS1 $n=9 ;$ WT+CBX $n=7 ;$ APP/PS1+CBX $n=3$ )

communication remained similar to that of wild-type (WT) mice and that HCs were chronically activated in all hippocampal astrocytes of mice bearing $A \beta$ plaques. They were predominantly composed of $\mathrm{Cx} 43$ whose openings were triggered by high intracellular $\mathrm{Ca}^{2+}$ concentration $\left(\left[\mathrm{Ca}^{2+}\right]_{\mathrm{i}}\right)$. Pannexin1 was also a minor $\mathrm{HC}$ contributer restricted to astrocytes contacting plaques and triggered by inflammation. $\mathrm{HC}$ activation contributed to maintain high $\left[\mathrm{Ca}^{2+}\right]_{i}$ within astrocytes and allowed for gliotransmitter release that likely led to neuronal suffering. The latter was significantly reduced in
APP/PS1 mice with an astroglial Cx43 deletion, opening the way for targeting $\mathrm{Cx} \mathrm{HCs}$ to alleviate neuronal damages in $\mathrm{AD}$.

\section{Results}

Gap junctional communication is not modified in APP/ PS1 astrocytes. The APP/PS1 mice used in our experiments accumulate $A \beta$ plaques with age in the cortex and the hippocampus (Figure 1a). The astroglial phenotype differed 

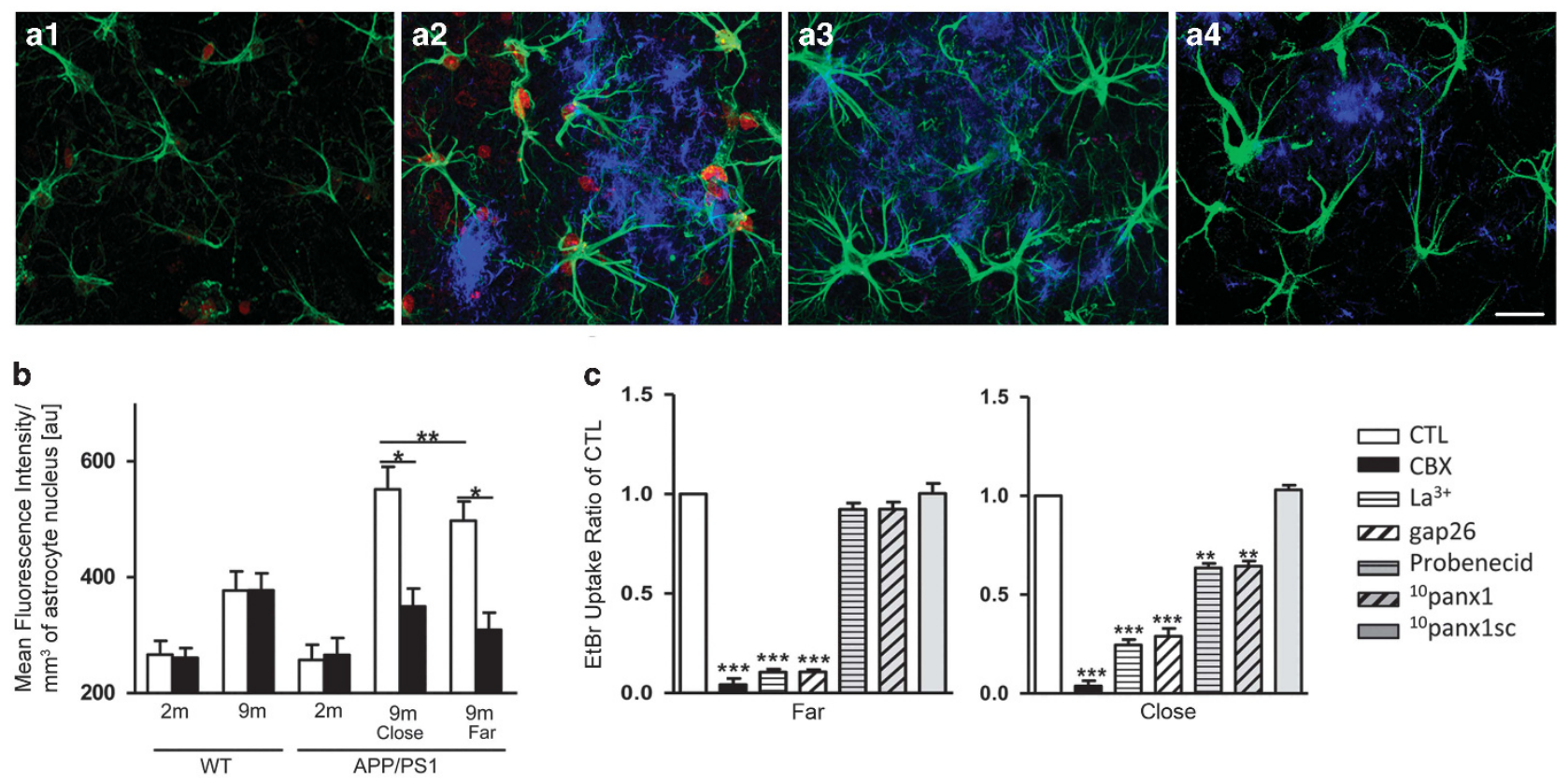

Figure 2 HCs are activated in astrocytes of old APP/PS1 mice. (a1-a4) EtBr fluorescent signal (red) in hippocampal slices of 9-month-old mice stained for GFAP (green) and $\mathrm{A} \beta$ (blue). In WT mice (a1), the signal was low compared with the bright signal in APP/PS1 mice (a2) that was suppressed by CBX (200 $\mu \mathrm{M})$ (a3) and undetectable when Ethidium homodimer $(10 \mu \mathrm{M})$ was used (a4); scale bar, $30 \mu \mathrm{m}$. (b) The mean fluorescence intensity of EtBr signal per astrocyte nucleus from WT and APP/PS1 mice measured at the ages indicated is expressed in arbitrary units (au) as mean \pm S.E.M. $\left({ }^{*} P<0.05,{ }^{* *} P<0.01\right.$; Student's $t$-test, $n=5$ ). (c) Histograms showing EtBr uptake in astrocytes far and close to plaques in presence of a series of $\mathrm{HC}$ blockers expressed as a ratio of control (CTL) conditions (without blockers) ${ }^{* *} P<0.01,{ }^{* * *} P<0.001$ versus $C T L$; ANOVA Dunnett's test; mean \pm S.E.M., $n=5)$

according to their proximity to $A \beta$ plaques, allowing to distinguish two populations (Figure $1 b$ ): reactive astrocytes contacting plaques with widened processes and enhanced GFAP staining defined as 'close', and astrocytes located at $\geq 50 \mu \mathrm{m}$ from plaques, named 'far' that showed neither signs of hypertrophy nor atrophy. We have compared gap junctional communication in hippocampal astrocytes of 9-month-old APP/PS1 and WT mice by using fluorescence recovery after photobleaching (FRAP) on brain slices loaded with SR101, a gap junction-permeant dye selectively taken up by astrocytes (Figure 1c). The kinetics of FRAP in photobleached astrocytes were similar in APP/PS1 and WT mice (Figure 1d) and reached $68.1 \pm 3.2 \%$ and $61.1 \pm 4.3 \%$, respectively, after 20 min (Figure 1e). In both genotypes, around $40 \%$ of this recovery was inhibited by CBX. Moreover, FRAP was similar in astrocytes 'close' and 'far' $(69.0 \pm 4.6 \%$ and $70.0 \pm 5.0 \%$, respectively), indicating that astroglial gap junctional communication was maintained in APP/PS1 mice and unaffected by the reactive or non-reactive status of astrocytes.

Increased membrane permeabilization in APP/PS1 astrocytes. HC activation was analyzed in acute hippocampal slices using EtBr uptake assay. ${ }^{25}$ First, EtBr fluorescent signal in GFAP-stained astrocytes nuclei, taken as an index of uptake, was examined in 9-month-old APP/PS1 and WT mice. This signal was faint in WT mice (Figure 2a1) compared with the bright signal in APP/PS1 mice (Figure 2a2). In the latter, CBX reduced EtBr signal to WT level (Figure 2a3), indicating that most of dye uptake occurred through $\mathrm{HCs}$. In addition, no unspecific uptake due to membrane damage in unhealthy cells was detected by using Ethidium homodimer (Figure 2a4). Then, EtBr fluorescence was quantified in young (2-month-old) and old (9-month-old) mice (Figure 2b). In young WT and APP/PS1 mice without plaques, the fluorescent signal was low and unaffected by CBX. This was also true in old WT mice, although the fluorescent signal was higher. In contrast, in old APP/PS1 mice bearing plaques, $\mathrm{EtBr}$ signal was strongly increased in reactive astrocytes contacting plaques (close) and to a lesser extent in non-reactive astrocytes far from plaques (Figure $2 b$ ); note that both were reduced to WT levels by CBX, confirming that $\mathrm{HCs}$ were activated in astrocytes.

To determine the molecular substrate of $\mathrm{HC}$ activity, we have used several $\mathrm{HC}$ blockers to discriminate between $\mathrm{Cx}$ and pannexin $\mathrm{HC}$ contribution ${ }^{25}$ and quantified $\mathrm{EtBr}$ signal in reactive astrocytes contacting plaques and in non-reactive astrocytes distant from plaques. Carbenoxolone, which blocks both $\mathrm{HC}$ families, abolished $\mathrm{EtBr}$ uptake in astrocytes, whether 'far' or 'close' (Figure 2c). The pannexin blockers, probenecid and ${ }^{10}$ panx 1 , inhibited $36.4 \pm 2.3 \%$ and $35.5 \pm 2.6 \%$, respectively, of EtBr uptake in astrocytes contacting plaques, but had no effect on astrocytes 'far'. Accordingly, EtBr uptake was strongly reduced by $\mathrm{Cx}$ blockers, $\mathrm{La}^{3+}$ and Gap26, in astrocytes 'close' (75.4 \pm 2.7 and $71.1 \pm 4.0 \%$ inhibition) and quite abolished in astrocytes 'far' (89.5 \pm 1.5 and $89.5 \pm 1.1 \%$ inhibition). We have also examined whether $\mathrm{HCs}$ remained activated in older mice (15 months old, Supplementary Figure 1), in which the high plaque load precluded the distinction between close and far astrocytes because most of them contacted plaques and/or small $A \beta$ deposits. 
In these cells, EtBr signal was nearly abolished by CBX (97.2 $\pm 0.6 \%$ inhibition), strongly reduced $(74.9 \pm 6.8$ and $75.5 \pm 2.5 \%$ inhibition) by $\mathrm{Cx}$ blockers, $\mathrm{La}^{3+}$ ions and Gap26, and partially inhibited $(39.5 \pm 3.3 \%)$ by the pannexin blocker ${ }^{10}$ panx1. Hence, their $\mathrm{EtBr}$ uptake profile was similar to that of reactive astrocytes close to plaques in younger 9-month-old APP/PS1 mice. Altogether, these data show that $\mathrm{HCs}$ are activated in all astrocytes of APP/PS1 mice bearing $\mathrm{A} \beta$ plaques with a major contribution of $\mathrm{Cxs}$ and a minor involvement of Panx1 in astrocytes contacting plaques.

Cx43 is the major contributor to HC activity in APP/PS1 astrocytes. Gap26, which targets $\mathrm{Cx} 43$, and $\mathrm{La}^{3+}$ ions, which block all $\mathrm{Cx} \mathrm{HCs}$, had the same inhibitory effect on $\mathrm{HCs}$ in APP/PS1 astrocytes suggesting that Cx43 may be the main $\mathrm{Cx}$ involved. To verify this, two colonies of APP/PS1 mice were generated lacking either Cx30 through an ubiquitous deletion or $\mathrm{Cx} 43$ through an astrocyte-targeted deletion. EtBr uptake was measured in slices of 9-month-old mice of both genotypes (Figure 3). The pharmacological profile of $\mathrm{EtBr}$ uptake was similar in astrocytes from APP/ PS1Cx30KO and APP/PS1 mice (Figure 3a): the EtBr signal was reduced by $89.5 \pm 8.0 \%$ and $64.4 \pm 6.8 \%$ by $\mathrm{Cx}$ blockers in astrocytes 'far' and 'close', respectively. In the latter, $30.9 \pm 4.3 \%$ of the signal was blocked by ${ }^{10}$ panx 1 . These results indicated that $\mathrm{C} \times 30$ was not involved in astroglial $\mathrm{HC}$ activity in APP/PS1 mice.

In mice lacking $\mathrm{Cx} 43$ in astrocytes (APP/PS1Cx43KO), the $\mathrm{EtBr}$ signal was hardly detectable in astrocytes 'far', representing $8.4 \pm 2.6 \%$ of that measured in APP/PS1 astrocytes, confirming the major contribution of $\mathrm{Cx} 43$ to the $\mathrm{HC}$ activity (Figure 3b). In astrocytes contacting plaques, the low $\mathrm{EtBr}$ signal represented $33.1 \pm 3.6 \%$ of that in APP/PS1 mice and was abolished by CBX or pannexin blockers indicating that it was mediated by Panx1 HCs. The residual EtBr signal detected in astrocytes 'far' was also abolished by CBX and pannexin inhibitors, likely resulting from gap junction-channelmediated propagation of the $\mathrm{EtBr}$ taken up by astrocytes 'close' through Panx1 HCs. Indeed, gap junctional communication was maintained in APP/PS1Cx43KO mice although reduced, compared with APP/PS1 mice (Supplementary Figure 2). Altogether, these data showed that Cx43 HCs were activated in hippocampal astrocytes of APP/PS1 mice whatever their distance to plaques and Panx1 HCs were minor contributors restricted to reactive astrocytes contacting plaques.

\footnotetext{
Mechanisms underlying $\mathrm{HC}$ activation in APP/PS1 astrocytes. To determine whether inflammation triggered $\mathrm{HC}$ opening in APP/PS1 astrocytes, brain slices of 9-month-old mice were acutely treated with minocycline that attenuates microglial activation: ${ }^{26}$ indeed, microglia exhibited reduced lba1 immunostaining and lost their activated morphology associated with plaques (Figure $4 a$ ). Also, IL-1 $\beta$ content was significantly reduced and TNFa tended to decrease (Figure 4b). EtBr uptake was not affected by minocycline in astrocytes 'far' (Figure 4c) but was reduced by $24.5 \pm 2.3 \%$ in astrocytes contacting plaques (Figure 4d), suggesting that the anti-inflammatory treatment blocked Panx1 HCs restricted to these astrocytes. This was confirmed by the
}
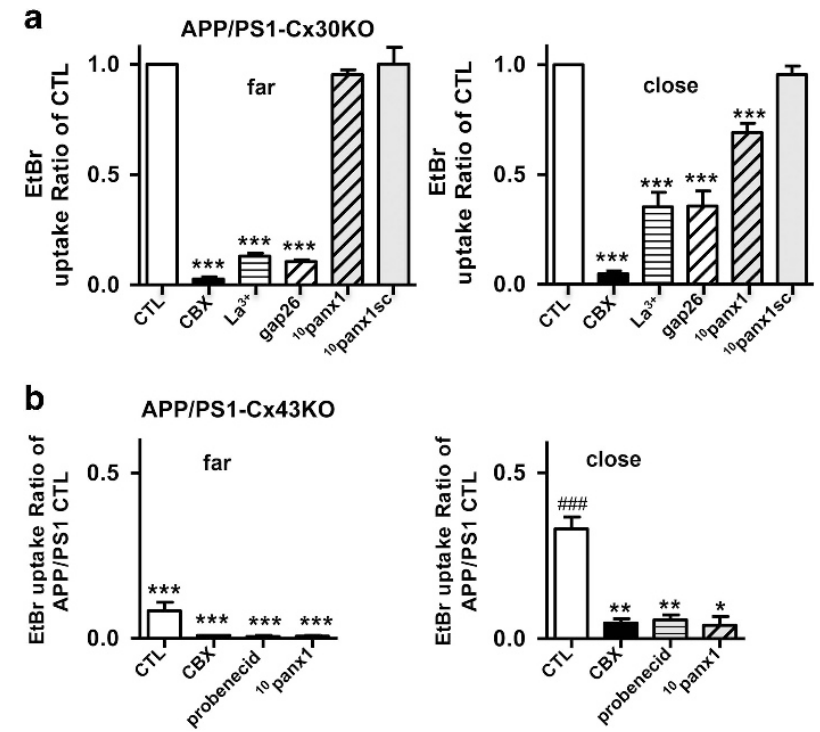

Figure $3 \mathrm{Cx} 43$ is the main component of HCs in astrocytes of APP/PS1 mice. Quantification analysis of EtBr uptake in the presence of indicated $\mathrm{HC}$ blockers in astrocytes far (left) and close (right) to plaques in 9-month-old APP/PS1 mice lacking $\mathrm{C} \times 30$ (a) or lacking $\mathrm{C} \times 43$ in astrocytes (b). In (a), EtBr uptake is expressed as a ratio of control (CTL) condition without blockers $\left({ }^{* \star} P<0.01,{ }^{* \star *} P<0.001\right.$, versus CTL; ANOVA Dunnett's test; mean \pm S.E.M., $n=5$ ). In (b), the residual EtBr uptake in APP/PS1Cx43KO mice is expressed as a ratio of values obtained in age-matched APP/PS1 mice in control condition ( ${ }^{* *} P<0.01,{ }^{* * *} P<0.001$, versus APP/PS1 CTL; ANOVA Dunnett's test; mean \pm S.E.M., $n=4$ )

absence of additive effect of the Panx1 blocker probenecid in minocycline-treated slices (Figure 4d). Interestingly, similar results were obtained in slices treated by a mixture of IL-1 $\beta$ and TNFa antagonists (Figures $4 \mathrm{c}$ and $\mathrm{d}$ ). These data indicate that inflammation triggered Panx1 $\mathrm{HC}$ activity in astrocytes but did not significantly affect $\mathrm{Cx} 43 \mathrm{HCs}$.

$\mathrm{C} \times 43 \mathrm{HC}$ opening is known to be regulated by $\left[\mathrm{Ca}^{2+}\right]_{i}$ and its increase in Cx43-transfected cells resulted in $\mathrm{HC}$ activation. ${ }^{27}$ Hence, the elevated resting $\left[\mathrm{Ca}^{2+}\right]_{\mathrm{i}}$ reported in APP/PS1 cortical astrocytes ${ }^{28}$ could trigger $\mathrm{Cx} 43 \mathrm{HC}$ activation. First, we confirmed that resting $\left[\mathrm{Ca}^{2+}\right]_{i}$ was elevated in APP/PS1 hippocampal astrocytes by comparing the fluorescence intensity of astrocytes in Fluo-4 AM loaded slices of APP/PS1 and WT mice (Figures $5 a$ and $b$ ). Then, to determine whether high $\left[\mathrm{Ca}^{2+}\right]_{i}$ regulated APP/PS1 astroglial $\mathrm{HC}$ activation, slices were treated with BAPTA-AM that decreased $\left[\mathrm{Ca}^{2+}\right]_{\mathrm{i}}$ under basal level in astrocytes (Figure $5 \mathrm{~b}$ ). In this condition, EtBr uptake was abrogated (Figure $5 \mathrm{c}$ ). As increased $\left[\mathrm{Ca}^{2+}\right]_{\mathrm{i}}$ can result from $\mathrm{Ca}^{2+}$ release from intracellular stores and/or $\mathrm{Ca}^{2+}$ influx through activated membrane receptors, the effect of drugs acting on these two pathways was tested on astroglial $\left[\mathrm{Ca}^{2+}\right]_{\mathrm{i}}$ in APP/PS1 mice (Figure $5 \mathrm{~d}$ ). Inhibitors of the $\mathrm{IP}_{3}$ pathway, U73122 and 2-APB, and of ryanodine receptors (dantrolene) significantly reduced $\left[\mathrm{Ca}^{2+}\right]_{\mathrm{i}}$ towards WT levels. Also, inhibitors of mGluR5 receptors, MPEP or SIB1757, and of P2 purinergic receptors, suramin or PPADS, reduced $\left[\mathrm{Ca}^{2+}\right]_{i}$ to the same extent. When $\mathrm{HC}$ activity was tested in the presence of each inhibitor, EtBr uptake was quite abolished $(\geq 90 \%$ inhibition) in astrocytes 'far' (Figure $5 \mathrm{e}$ ) and reduced by $70 \%$ in reactive astrocytes contacting plaques (Figure $5 f$ ). In the latter, 


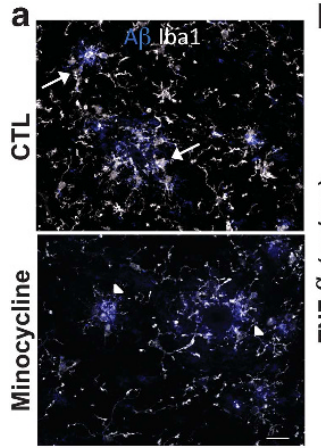

\section{b}
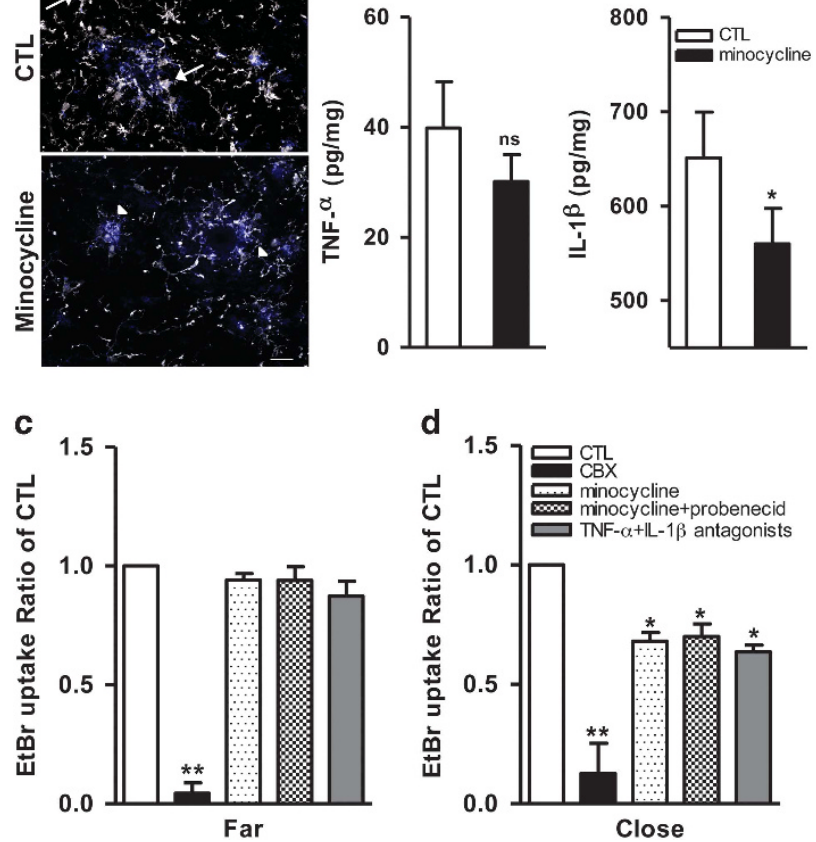

Figure 4 Inflammation triggers Panx HCs. (a) Immunostainings for Iba1 (white) and $\mathrm{A} \beta$ plaques (blue) of brain hemisphere slices from 9-month-old APP/PS1 maintained $2 \mathrm{~h}$ in ACSF alone (CTL) or with minocycline. Scale bar, $20 \mu \mathrm{m}$. (b) The levels of TNF $\alpha$ and IL-1 $\beta$ measured by ELISA in APP/PS1 slices were reduced after an acute treatment with minocycline $(50 \mathrm{nM})$ during $2 \mathrm{~h}$. (c and d) Quantification analysis of EtBr uptake in astrocytes far (c) and close (d) to plaques from APP/PS1 slices treated with the indicated agents. EtBr uptake is expressed as a ratio of control conditions. Anti-inflammatory treatments affected only the astrocytes close to plaques where $\mathrm{EtBr}$ uptake was reduced by $30 \%$ with no additive effect of Panx blocker $\left({ }^{*} P<0.05,{ }^{*} P<0.01\right.$, versus CTL; ANOVA Dunnett's test; mean \pm S.E.M., $\left.n=5\right)$

the residual EtBr uptake measured in physiological $\left[\mathrm{Ca}^{2+}\right]_{i}$ was abrogated by probenecid or minocycline that prevented Panx 1 $\mathrm{HC}$ activation (Figure $5 \mathrm{~g}$ ), demonstrating that high $\left[\mathrm{Ca}^{2+}\right]$ triggered $\mathrm{Cx} 43 \mathrm{HCs}$ but not Panx1 HCs.

Altogether, these results indicate that the mechanisms involved in $\mathrm{Cx} 43$ versus Panx $1 \mathrm{HC}$ activation are distinct: high $\left[\mathrm{Ca}^{2+}\right]_{i}$ triggers $\mathrm{Cx} 43 \mathrm{HCs}$ whereas inflammatory signals regulate Panx1 $\mathrm{HC}$ activity.

HC activity supports $\mathrm{Ca}^{2+}$ influx and gliotransmitter release in APP/PS1 mice. Activated $\mathrm{HCs}$ allow for $\mathrm{Ca}^{2+}$ influx within astrocytes; ${ }^{22}$ hence, we have analyzed the effect of $\mathrm{HC}$ blockers on astroglial $\left[\mathrm{Ca}^{2+}\right]_{i}$ in APP/PS1 mice. Carbenoxolone or Gap26 reduced astroglial $\left[\mathrm{Ca}^{2+}\right]_{i}$ to levels close to WT (Figure 6a). Accordingly in APP/PS1Cx43KO, $\left[\mathrm{Ca}^{2+}\right]_{\mathrm{i}}$ was reduced to the same extent indicating that activated $\mathrm{HCs}$ contributed to the increased $\left[\mathrm{Ca}^{2+}\right]_{i}$ in APP/ PS1 astrocytes.

Also, we examined whether gliotransmitter release resulting of $\mathrm{HC}$ activation ${ }^{14}$ occurred in APP/PS1 mice. ATP released from brain slices was measured by bioluminescence. The amount of ATP released from APP/PS1 slices $(13.7 \pm 1.0 \mathrm{nmol} / \mathrm{mg}$ protein) was about twice that from WT $(6.1 \pm 1.1 \mathrm{nmol} / \mathrm{mg}$ protein) (Figure $6 \mathrm{~b})$ and was reduced to
WT levels by CBX or Gap26 $(6.1 \pm 1.4$ and $7.0 \pm 1.0 \mathrm{nmol} / \mathrm{mg}$ protein, respectively). The peptide ${ }^{10}$ panx 1 reduced ATP release to a lesser extent $(8.5 \pm 1.4 \mathrm{nmol} / \mathrm{mg}$ protein). Finally, the amount of ATP released from APP/PS1Cx43KO and WT slices was similar, confirming that activated $\mathrm{C} \times 43 \mathrm{HCs}$ contributed to ATP release in APP/PS1 mice.

L-Glutamate release was evaluated in similar samples by measuring its respective content in the extracellular medium and the slices, then by calculating their ratio as an index of release (Figure 6c). Glutamate release was higher in APP/PS1 than in WT mice and was strongly reduced by CBX $(66.7 \pm 15.7 \%)$, Gap26 $(93.6 \pm 4.9 \%)$ and ${ }^{10}$ panx1 $(80.1 \pm 5.5 \%)$. The level of glutamate release from APP/ PS1Cx43KO mice was reduced $(48.5 \pm 15.4 \%)$ compared with APP/PS1 mice and returned to WT level.

Finally, contrary to ATP and glutamate, GABA release (Figure $6 \mathrm{~d}$ ) was not significantly affected by CBX or mimetic peptides and was equivalent in all genotypes.

The lack of astroglial Cx43 prevents neuronal damage in APP/PS1 mice. As gliotransmitter release can be neurotoxic, neuronal suffering was compared in 9-month-old APP/PS1 and APP/PS1Cx43KO mice by testing two parameters reflecting neuronal damage. First, the oxidative stress was examined in hippocampal neurons using the mitochondrial superoxide indicator MitoSOX in living slices. A bright fluorescent signal was detected in the pyramidal cell layer of APP/PS1 but not WT mice (Figure 7a), indicating an accumulation of superoxide anions in $A D$ mice neurons as previously reported. ${ }^{29}$ In contrast, the MitoSOX signal was hardly detectable in APP/PS1Cx43KO hippocampal neurons like in WT mice (Figure 7b). Interestingly, such reduction of oxidative stress was not observed when APP/PS1 slices were acutely treated with Gap26, indicating that a short-term $\mathrm{HC}$ block was not sufficient to reduce neuronal suffering. Second, another characteristic of neuronal damage is the presence of neuritic dystrophies associated with plaques. ${ }^{1,30}$ They were examined in brain sections from APP/PS1 and APP/PS1Cx43KO mice immunostained for A $\beta$ and RTN3, a marker of dystrophic neurites in AD. ${ }^{31}$ Bright RTN3 immunoreactive bulbous structures typical of dystrophic neurites (RIDNs) were detected within and around plaques in both genotypes. However, in APP/PS1Cx43KO mice, RIDNs were less abundant in large dense core plaques and rarely present in small plaques (Figure 7c). A highly significant reduction $(49.4 \pm 1.7 \%)$ of RIDNs was found in APP/PS1Cx43KO compared with APP/PS1 mice (Figure 7d). Such reduced neuronal damage occurred although the density and size of $A \beta$ plaques was not significantly different between both genotypes: 290 versus 270 plaques $/ \mathrm{mm}^{2}$ of brain area among which 50 versus 48 large plaques $/ \mathrm{mm}^{2}$ (diameter $\geq 20 \mathrm{~mm}$ ) in APP/PS1 and APP/PS1Cx43KO mice, respectively (Supplementary Figure 3). Altogether, these observations indicate that the lack of $\mathrm{Cx} 43$ in astrocytes and the resultant reduction in $\mathrm{HC}$ activity and gliotransmisson significantly attenuate neuronal damage in APP/PS1 mice. 


\section{b}
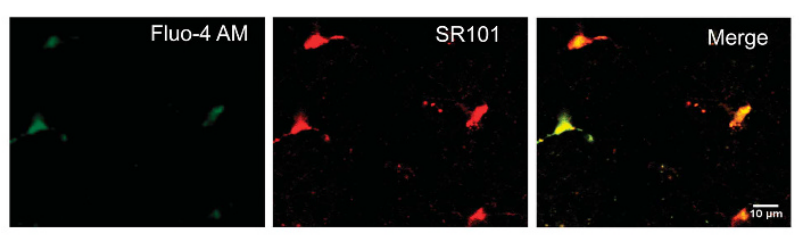
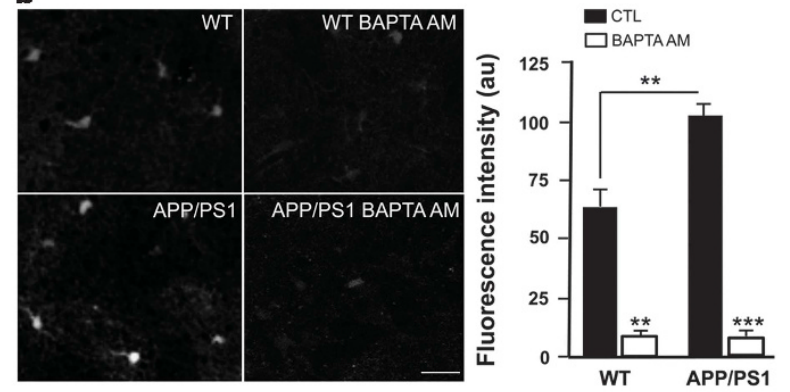

d

c
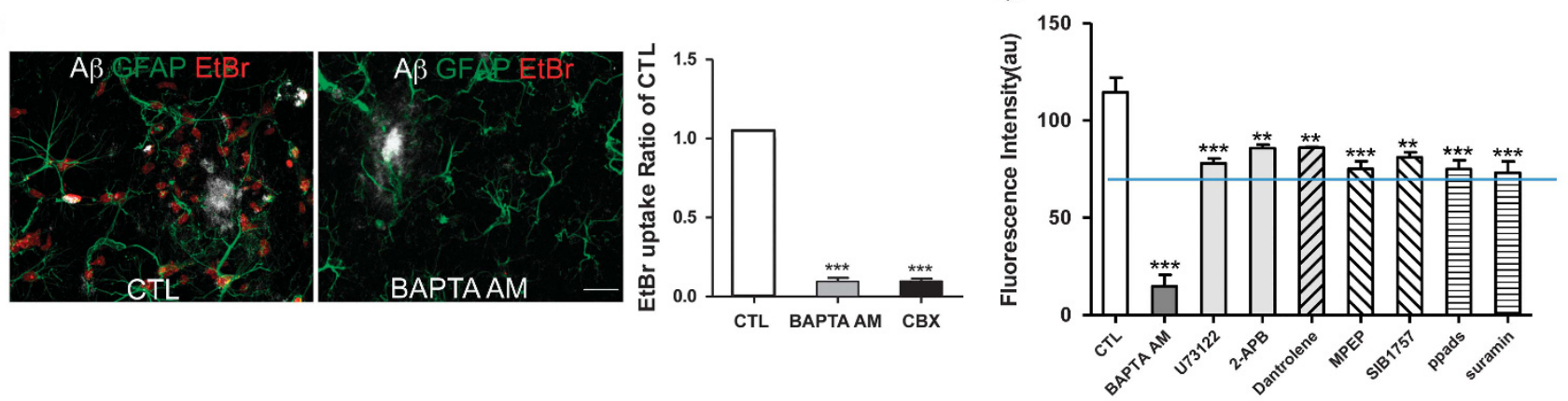

e

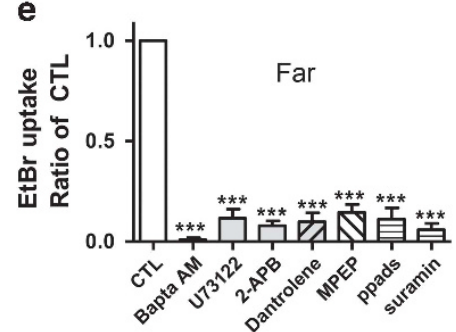

f

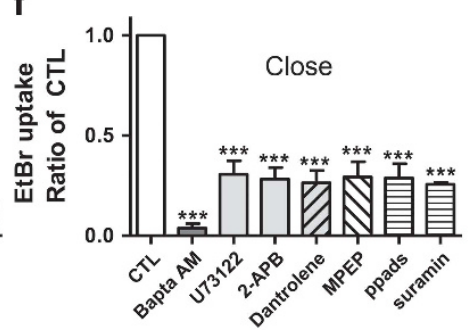

g

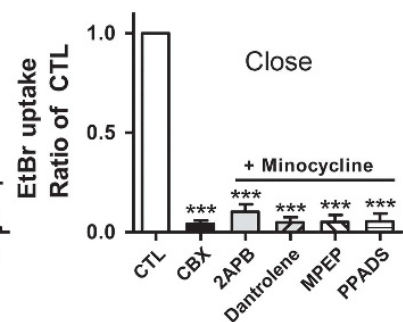

Figure 5 High $\left[\mathrm{Ca}^{2+}\right]_{i}$ triggered Cx43 HCs in astrocytes of APP/PS1 mice. (a) Images of hippocampal slices of 9-month-old APP/PS1 mice preloaded with Fluo-4 AM (green, left) and labeled with SR101 (red, middle). Merged image (yellow, right) shows that astrocytes selectively loaded Fluo-4 AM. Scale bar, $10 \mu$ m. (b) Images of Fluo-4 AM fluorescent signal in hippocampal slices of 9-month-old WT and APP/PS1 under control condition (left) or treated 45 min with BAPTA-AM (right). Scale bar, $30 \mu \mathrm{m}$. Averaged data of Fluo-4 AM fluorescence levels in astrocytes from WT and APP/PS1 brain slices treated or not with BAPTA-AM expressed in arbitrary units (au) ${ }^{\star \star} P<0.01$, ${ }^{* \star \star} P<0.001$; Student's t-test; mean \pm S.E.M., $n=3$ ) showing that $\left[\mathrm{Ca}^{2+}\right]_{i}$ was elevated in APP/PS1 astrocytes and drastically reduced after BAPTA-AM treatment. (c) Images of EtBr signal (red) in GFAP-stained astrocytes (green) in brain slices of 9-month-old APP/PS1 mice with A $\beta$ plaques (white) in absence (CTL) or presence of BAPTA-AM. Scale bar, $20 \mu$ m. The histogram shows that BAPTA-AM suppressed EtBr uptake as efficiently as CBX ${ }^{\star \star \star} P<0.001$, versus $\mathrm{CTL}$; Student's $t$-test; values represent the mean \pm S.E.M., $n=3$ ) (d) Resting $\left[\mathrm{Ca}^{2+}\right]_{\mathrm{i}}$ levels expressed as the mean fluorescence intensity of Fluo-4 AM loaded in astrocytes of APP/PS1 brain slices in ACSF alone (CTL) or in presence of the indicated agents. Physiological level in WT mice is indicated by the blue line. $\left({ }^{* \star} P<0.01,{ }^{* \star *} P<0.001\right.$, versus CTL; ANOVA Dunnett's test; mean \pm S.E.M., $\left.n=3\right)$. $(\mathbf{e}-\mathbf{g})$ Quantification analysis of EtBr uptake in astrocytes far $(\mathbf{e})$ and close ( $\mathbf{f}$ and $\mathbf{g})$ to plaques in the presence of these agents to which Panx blocker probenecid ( $\mathbf{g}$, left) or minocycline was added (g, right) that prevented Panx1 HC triggering. In both conditions, EtBr uptake was abrogated in astrocyte-contacting plaques. ( ${ }^{\star \star \star} P<0.001$, versus $\mathrm{CTL}$; ANOVA Dunnett's test; mean \pm S.E.M., $n=3$ )

\section{Discussion}

In the present study, we have used a non-aggressive murine model of FAD to examine Cx channel functions in hippocampal astrocytes. Most analyses were performed in 9-month-old mice, when amyloid plaques are scattered enough to analyze Cx functions both in reactive astrocytes contacting plaques and non-reactive astrocytes located far away.

First, we have shown that gap junction channel function was similar in hippocampal astrocytes of APP/PS1 and WT mice, confirming observations reported in other FAD models. ${ }^{12,13}$ Interestingly, gap junction-mediated communication was not affected by the proximity of astrocytes to $A \beta$ plaques where clustered activated microglia represent a source of inflammatory cytokines. Such observation contrasts with the reduced gap junctional communication of astrocytes acutely treated with proinflammatory cytokines ${ }^{19}$ (but see Abudara et al. $^{22}$ ) or after an in vivo inflammatory insult induced by a brain abscess. ${ }^{20}$ Interestingly, in the latter situation, gap junctional communication decreased only in the inflammatory nidus but remained normal in regions away from the abscess.

Second, we revealed that $\mathrm{Cx} 43 \mathrm{HCs}$ were chronically activated in hippocampal astrocytes when $A \beta$ plaques are present, whatever their distance from the plaques. However, $\mathrm{HC}$ activation was prominent in the astrocytes contacting plaques, which is in line with their higher $\mathrm{C} \times 43$ content $^{7-9}$ and 
a

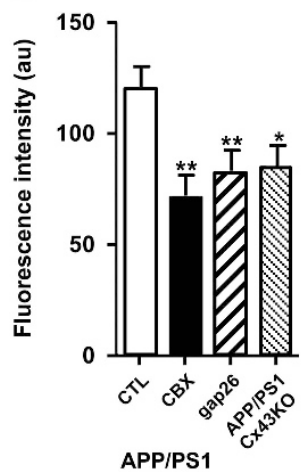

b

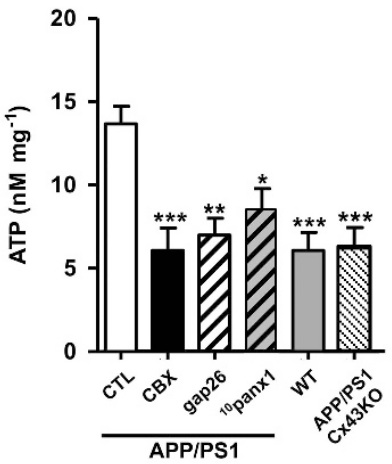

c

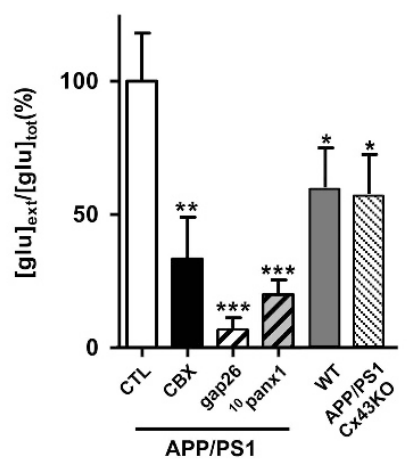

d

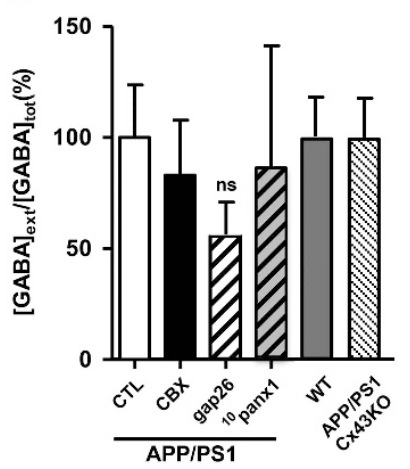

Figure $6 \mathrm{HC}$ activity supports $\mathrm{Ca}^{2+}$ influx and gliotransmitter release in APP/PS1 mice. (a) Resting $\left[\mathrm{Ca}^{2+}\right]_{\mathrm{i}}$ levels expressed as mean Fluo-4 AM fluorescence intensity in arbitrary units (au) in astrocytes of APP/PS1 brain hemisphere slices treated or not with CBX or gap26 and from APP/PS1CX43KO slices under control condition, showing that acute or long-term HC inhibition in APP/PS1 mice decreased $\left[\mathrm{Ca}^{2+}\right]_{\mathrm{i}}\left({ }^{*} P<0.05,{ }^{*}{ }^{*} P<0.01\right.$, versus APP/PS1 CTL; Student's t-test; mean \pm S.E.M., $\left.n=3\right)$. (b-d) Gliotransmitter levels released from brain hemisphere slices of APP/PS1 (treated or not with $\mathrm{HC}$ blockers), WTor APP/PS1Cx43KO mice (ns, not significant, ${ }^{*} P<0.05,{ }^{* *} P<0.01,{ }^{* \star *} P<0.001$ versus CTL; ANOVA Dunnett's test; mean \pm S.E.M., $n=5$ ). ATP $(\mathbf{b})$ and glutamate (c) release from APP/PS1 slices were reduced after pretreatment with CBX, gap26, ${ }^{10}$ panx1 and returned to wild-type level in APP/PS1 mice lacking Cx43. (d) GABA release was not significantly affected by HC blockers and was similar in mice of all genotypes

the contribution of Panx1 HCs. Although the issue of the molecular nature of astroglial HCs was highly debated, accumulating evidence indicates that both families of $\mathrm{HC}$-forming proteins can be activated in astrocytes: $\mathrm{Cx} 43$ in response to $A \beta$ treatment, ${ }^{21}$ ischemia-like conditions ${ }^{32}$ or inflammation, ${ }^{19,33}$ and Panx1 HCs triggered by P2X7 receptor stimulation, elevated $\mathrm{K}^{+34}$ or inflammation. ${ }^{20}$ Their relative contribution likely depends on the triggering event, timing after injury or inflammatory context. Our data provide further evidence that the nature of activated HCs in astrocytes depend on their local environment.

In this context, it is worth noting that $\mathrm{Cx}$ and pannexin $\mathrm{HC}$ activation were driven by different mechanisms in APP/PS1 mice. Inflammatory signals triggered Panx1 HCs solely in astrocytes contacting plaques where activated microglia are concentrated. ${ }^{30}$ We cannot exclude that other stimuli in the plaque microenvironment participated in Panx1 HC openings. A local elevation in extracellular $\mathrm{K}^{+}$resulting from neuronal hyperexcitability nearby plaques ${ }^{35}$ could also promote Panx1 openings as reported in culture. ${ }^{36}$ Also, ATP could trigger Panx1 HC openings by activating P2X7 receptors whose expression is increased in reactive glia nearby plaques. ${ }^{37}$ In contrast, the main parameter underlying $\mathrm{Cx} 43 \mathrm{HC}$ opening in APP/PS1 mice was the increased $\left[\mathrm{Ca}^{2+}\right]_{i}$. $A \beta$ oligomers dysregulate $\mathrm{Ca}^{2+}$ homeostasis in astrocytes, especially through increased expression of key components of $\mathrm{Ca}^{2+}$ signaling, for example, mGluR5 receptors and IP3R1. ${ }^{38,39}$ Hence, treatments that reduced $\left[\mathrm{Ca}^{2+}\right]_{\mathrm{i}}$, either by blocking pathways of $\mathrm{Ca}^{2+}$ release from internal stores or using antagonists of membrane receptors whose activation induces $\mathrm{Ca}^{2+}$ increase, led to a concomitant inhibition of $\mathrm{Cx} 43 \mathrm{HC}$ activity.

Interestingly, we have shown that, like in culture ${ }^{40}$ or acute slices, ${ }^{22} \mathrm{Cx} 43 \mathrm{HCs}$ can also provide a pathway for $\mathrm{Ca}^{2+}$ entry in APP/PS1 astrocytes, because astroglial $\left[\mathrm{Ca}^{2+}\right]_{\mathrm{i}}$ was reduced in brain slices after acute pharmacological $\mathrm{Cx} 43$ $\mathrm{HC}$ block or in APP/PS1Cx43KO mice. Therefore, a vicious circle takes place in astrocytes in which high $\left[\mathrm{Ca}^{2+}\right]_{i}$ triggers $\mathrm{C} \times 43 \mathrm{HC}$ openings that in turn allow $\mathrm{Ca}^{2+}$ entry contributing to maintain elevated $\left[\mathrm{Ca}^{2+}\right]_{\mathrm{i}}$. HC-dependent ATP and glutamate release can amplify this vicious circle by stimulating in an autocrine manner purinergic and glutamatergic metabotropic receptors that contribute also to maintain high $\left[\mathrm{Ca}^{2+}\right]_{\mathrm{i}}$ in APP/PS1 astrocytes. ${ }^{28}$ One consequence of this vicious circle is a chronic $\mathrm{Cx} 43 \mathrm{HC}$ activation leading to gliotransmitter release. Such release can occur directly via $\mathrm{HCs}$, because $\mathrm{Cx} 43 \mathrm{HCs}$ represent a pathway for glutamate release, ${ }^{41,42}$ and both $\mathrm{Cx}^{43,44}$ and Panx HCs can release ATP. ${ }^{15,34}$ Indeed, in another FAD model, astroglial $\mathrm{Cx}$ HCs were proposed as the source of ATP that triggered P2Y1 receptors leading to increased calcium transients and calcium waves in astrocytes. $^{23}$ However, we cannot exclude that other $\mathrm{Ca}^{2+}$ dependent pathways participate in such gliotransmitter release. In contrast, GABA release was not significantly affected in APP/ PS1Cx43KO mice confirming that it occurred through a pathway independent of $\mathrm{HC}$ activation. ${ }^{45}$ The genetic suppression of $\mathrm{Cx} 43$ in APP/PS1 astrocytes allowed to reduce $\left[\mathrm{Ca}^{2+}\right]_{\mathrm{i}}$ as well as extracellular ATP and glutamate levels to WT levels, highly suggesting that the chronic activation of $\mathrm{Cx} 43 \mathrm{HCs}$ sustains this vicious circle in astrocytes.

The chronic gliotransmitter release involving activated HCs can have multiple consequences on neurons, deleterious and/or protective. First, an excess of extracellular glutamate could act on neuronal NMDA receptors, in particular extrasynaptic receptors, and contribute to dysregulate neuronal $\mathrm{Ca}^{2+}$ homeostasis and promote synaptic loss. ${ }^{46}$ Neuronal $\mathrm{Ca}^{2+}$ overload has numerous downstream deleterious consequences including structural neuritic alterations ${ }^{47}$ and increased oxidative stress, occurring early in $\mathrm{AD}^{48}$ Indeed, in APP/PS1 mice, oxidative stress was triggered in dystrophic neurites nearby plaques and propagated into the cell body leading to caspase-dependent death in some vulnerable cortical neurons. ${ }^{49}$ Second, an excess of ATP can also stimulate ionotropic (P2X) and metabotropic (P2Y) receptors that mediate multiple functions in brain cells. By activating P2X7 receptors in astrocytes and microglia, ATP could favor the rapid release of $\mathrm{IL}-1 \beta$, which is potentially neurotoxic. ${ }^{50}$ It might also act directly on neuronal purinergic receptors 

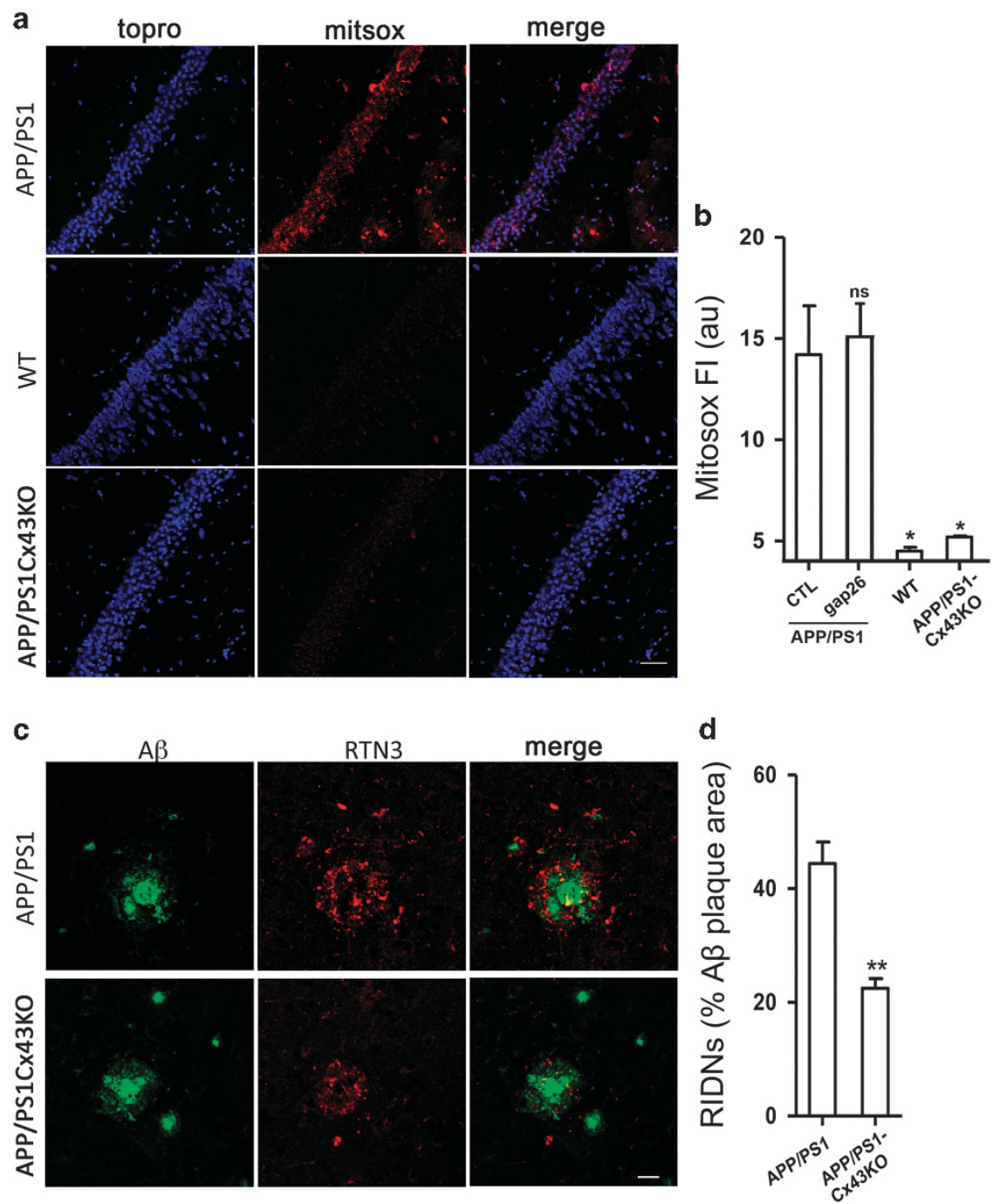

Figure 7 Reduced neuronal damage in APP/PS1 mice lacking astroglial Cx43. (a) Images of TO-PRO staining (blue) and MitoSOX signal (red) in the hippocampal pyramidal cell layer of mice of the indicated genotypes showing that the level of mitochondrial superoxide was high in APP/PS1 compared with WT and APP/PS1Cx43KO mice. Scale bar, $50 \mu \mathrm{m}$. (b) Quantification of the mean fluorescence intensity of MitoSOX in the pyramidal cell layer of indicated genotypes indicating that the lack of CX43 in APP/PS1 mice reduced the mitochondrial superoxide level to WT levels while an acute treatment of APP/PS1 slices with a Cx43 mimetic peptide had no effect $\left({ }^{*} P<0.05\right.$; Student's $t$-test; mean \pm S.E.M., $n=3$ ). (c) Images of immunostainings for A $\beta$ plaques (green) and RTN3 (red) in hippocampal sections from APP/PS1 and APP/PS1Cx43KO mice. RTN3 labeled dystrophic neurites appeared as bright red dots concentrated in and around A $\beta$ plaques and were less abundant in APP/PS1Cx43KO mice. Scale bar, $30 \mu \mathrm{m}$. (d) The histogram shows that the area occupied by RTN3 stained dystrophic neurites in A $\beta$ plaques was significantly smaller in APP/PS1Cx43KO versus APP/PS1 mice ${ }^{* *} P<0.01 ;$ unpaired Student's t-test; mean \pm S.E.M., $n=5$ )

leading to neuronal $\mathrm{Ca}^{2+}$ overload with its cascade of detrimental outcome. The lack of astroglial Cx43 in APP/PS1Cx43KO mice contributes to reduce oxidative stress and neuritic dystrophies in hippocampal neurons likely by tuning down glutamate and ATP release.

However, in the APP/PS1 mice used, no overt neuronal loss was reported except in few cortical neurons. ${ }^{49}$ This suggests that, despite elevated ATP and glutamate levels, compensatory neuroprotective mechanisms take place to prevent neuronal death. Pleiotropic neuroprotective effects of ATP were reported upon $\mathrm{P} 2 \mathrm{Y}$ receptor activation. ${ }^{51}$ For example, astroglial P2Y1 receptor activation can induce the release of the neuroprotective IL- $6,{ }^{52}$ while P2Y2 receptor activation can trigger $a$-secretase and promote growth factor release and
APP cleavage towards a soluble neuroprotective ectodomain sAPPa. ${ }^{53} \mathrm{P} 2 \mathrm{X} 7$ receptor activation can also promote sAPPs formation. ${ }^{54}$ In addition, ATP can convert into adenosine whose binding to $A 1$ receptors stimulates $P K C$ and increases sAPPa formation. Finally, glutamate also can sustain neuronal survival by triggering $m G$ luR 3 receptors leading to the release of the neuroprotective TGF $\beta$ and of SAPP $a .{ }^{55}$ Consequently, there is likely a balance between prosurvival and prodeath signaling in neurons that mitigates the neurodegenerative processes and prevents the last steps of neurotoxicity leading to death.

In conclusion, in FAD mice, functional changes in astrocytes can affect their interactions with neurons. The chronic activation of astroglial $\mathrm{HCs}$ shown here contributes to maintain 
a high $\left[\mathrm{Ca}^{2+}\right]_{i}$ in astrocytes that allows a sustained gliotransmitter release, which posit astrocytes as amplifiers of toxicity that participate with other actors in neuronal injury. The lack of $\mathrm{Cx} 43$ in astrocytes significantly reduces neuronal suffering in APP/PS1 mice. Cx43 HCs being accessible via the extracellular medium may represent interesting targets to design tools susceptible to alleviate neuronal damages.

\section{Materials and Methods}

Animals. $\mathrm{APP}_{\text {swe }} / \mathrm{PS}_{\mathrm{dEg}}^{24}$ and $\mathrm{C} 57 \mathrm{BI} / 6$ mice were obtained from Jackson Laboratories (Bar Harbor, ME, USA); APP $_{\text {swe }} / P 1_{\text {dEg }}$ Cx30-/- mice and

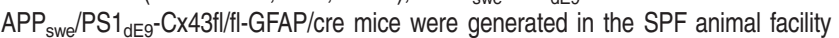
of the Collège de France by crossbreedings $\mathrm{APP}_{\text {swe }} / \mathrm{PS}_{\mathrm{dEg}}$ with $\mathrm{C} \times 30-/$ - and GFAP-creCx43fl/fl, respectively. Experiments were performed on mice of either sex according to the European Community Council Directives (2010/63/UE).

Acute brain slices. Acute brain hemisphere slices $(300 \mu \mathrm{m})$ were cut on a vibroslicer and transferred to a holding chamber where they rested on a nylon mesh, submerged in oxygenated artificial cerebrospinal fluid (ACSF) at room temperature (RT) for a stabilization period of $60 \mathrm{~min}$. The ACSF solution contained (in mM): $\mathrm{NaCl}$ (125); $\mathrm{KCl}(2.5) ; \mathrm{NaHCO}_{3}$ (25); $\mathrm{NaH}_{2} \mathrm{PO}_{4}$ (1.25); glucose (25); $\mathrm{MgCl}_{2}$ (1); $\mathrm{CaCl}_{2}$ (2).

Dye uptake in acute brain slices. Acute slices were incubated with the $\mathrm{HC}$ permeable fluorescent tracer Ethidium bromide (EtBr, Sigma-Aldrich, St Quentin Fallavier, France) for $10 \mathrm{~min}$ at $4 \mu \mathrm{M}$ final concentration at RT. To determine the sensitivity of $\mathrm{EtBr}$ uptake to $\mathrm{Cx}$ or pannexin $\mathrm{HCs}$ blockers, slices were preincubated in ACSF supplemented with each blocker during 15 min prior to dye application. The blockers used were: carbenoxolone (CBX, $200 \mu \mathrm{M}), \mathrm{La}^{3+}$ ions $(400 \mu \mathrm{M})$, probenecid $(1 \mathrm{mM})$ or mimetic peptides targeting Cx43 or pannexin1, Gap26 $(0.3 \mathrm{mg} / \mathrm{ml})$ and ${ }^{10}$ panx1 $(0.5 \mathrm{mg} / \mathrm{ml})$, respectively, and pannexin1 scrambled peptide $(0.5 \mathrm{mg} / \mathrm{ml})$ for control. Following EtBr incubation, slices were rinsed three times in ACSF, fixed for $1 \mathrm{~h}$ in $4 \%$ paraformaldehyde and processed for immunostainings.

Fixed slices were preincubated in PBS containing $0.2 \%$ gelatin and $1 \%$ TritonX100 (PBS*) for 30 min two times, and then incubated overnight at $4{ }^{\circ} \mathrm{C}$ in primary antibodies diluted in PBS*. Mouse or chicken antibodies anti-GFAP (1:500, SigmaAldrich and ABCAM, Cambridge, UK), rabbit anti-A $\beta$ (1:1000, Life Technologies, Thermo-scientific, France) and rabbit or goat anti-lba1 (1:500, Wako, Neuss, Germany) were used to detect astrocytes, $A \beta$ deposits and microglia, respectively. After $2 \times 30$ min washes in $\mathrm{PBS}^{*}$, sections were incubated for $2 \mathrm{~h}$ at $\mathrm{RT}$ with a mixture of Alexa-conjugated appropriate secondary antibodies (diluted in PBS* 1:2000, Molecular Probes, Eugene, OR, USA), washed and mounted in Fluoromount (Southern Biotechnology, Birmingham, AL, USA). These slices were examined at $\times 40$ with a confocal laser scanning microscope SP5, (Leica, Wetzlar, Germany). Four images covering $\mathrm{CA} 1$ to $\mathrm{CA} 3$ hippocampus were captured for each experimental condition. Stacks of 22 consecutive confocal images taken at $0.5-\mu \mathrm{m}$ intervals were acquired sequentially with three lasers (argon $488 \mathrm{~nm}, 561 \mathrm{~nm}$ for EtBr and $647 \mathrm{~nm}$ ).

$\mathrm{EtBr}$ fluorescent signal in astrocyte nuclei was analyzed using Mac Imaris 7.4.0 software. Cells that satisfied the following criteria were considered as $\mathrm{EtBr}^{+}$ astrocytes: (i) cells positive for GFAP; (ii) cells whose nuclei exhibited $\mathrm{EtBr}$ fluorescence intensity above the threshold defined in areas outside nuclei and (iii) cells whose nuclei volume was $>100 \mu \mathrm{m}^{3}$ (diameter $\geq 6 \mu \mathrm{m}$ ) to eliminate incomplete objects. Counts were carried out for 200 cells per condition. First, the percentage of $\mathrm{EtBr}^{+}$astrocytes was calculated among the population of $\mathrm{GFAP}^{+}$cells. Then, the fluorescence intensity per nucleus and the volume of the nuclei of $\mathrm{EtBr}^{+}$astrocytes were measured. The mean fluorescence intensity of the population of $\mathrm{EtBr}^{+}$ astrocytes per experimental condition was then calculated. EtBr uptake for each condition was determined by taking into account the percentage of $\mathrm{EtBr}^{+}$astrocytes and their mean fluorescence intensity. Finally, the EtBr uptake ratio in each condition was normalized to the control condition.

Fluorescence recovery after photobleaching (FRAP). To evaluate gap junction function, we have used FRAP to measure cell-to-cell exchange of a fluorescent diffusion tracer, ${ }^{25,56}$ sulforhodamine-101 (SR101) that is selectively taken up by astrocytes and passes through gap junctional channels. ${ }^{57}$ Acute brain hemisphere slices of 9-month-old WT, APP/PS1 and APP/PS1Cx43KO mice were prepared as described above. They were then incubated in $1 \mu \mathrm{M}$ SR101 at $37^{\circ} \mathrm{C}$ for $30 \mathrm{~min}$. After 20 min wash in ACSF, the slices were placed in the stage of a confocal microscope and perfused with oxygenated ACSF during the whole experiment. Acquisitions were performed using a Leica $\times 25$, NA $=0.95$, water immersion objective on a Leica SP5 MP microscope controlled by the Leica Acquisition Software. After excitation with the $561 \mathrm{~nm}$ line of laser, a baseline fluorescence was collected every $25 \mathrm{~s}$ during $200 \mathrm{~s}$. Then, the laser scanning was restricted to a square $(15 \mu \mathrm{m} \times 15 \mu \mathrm{m})$ covering the whole cell body of the target astrocyte with a zoom $\times 3$. Fifteen pulses of light at full power of the laser were applied to bleach this target area. Then, the normal recording configuration was reestablished and fluorescence recovery was recorded every $25 \mathrm{~s}$ during $20 \mathrm{~min}$. Images were analyzed offline: the mean fluorescence intensity of astrocyte cell body was measured with Image $\mathrm{J}$ software. $\mathrm{F}_{0}$ was regarded as the first value of the baseline recording. The fluorescence intensity of each timepoint was normalized to $F_{0}$ and then expressed as percentage of $F_{0}\left(F_{t} / F_{0} \%\right)$. The percentage of recovery was calculated by using the plateau value (the average of the last six values of the recording) subtracting the value of the first time point after photobleaching. All studies were performed at $45 \mu \mathrm{m}$ below the surface to ensure that the cells of interest had not been damaged during preparation. Carbenoxolone, which inhibits gap junction channels, was used as a negative control in these experiments.

TNF $\boldsymbol{\alpha}$ and IL-1 $\beta$ measurements by ELISA. Brain hemisphere slices from 9-month-old APP/PS1 mice ( $300 \mu \mathrm{m}$, two slices for each condition) were treated or not with minocycline $(50 \mathrm{nM}$, Sigma-Aldrich) during $2 \mathrm{~h}$, transferred into tubes, frozen and stored at $-80^{\circ} \mathrm{C}$ until processing. Slices were immersed in ice-cold lysis buffer containing (in mM) Tris-HCl 50, NaCl 100, EDTA 2, 1\% Triton-X100 and $1 \%$ protease inhibitor cocktail (Sigma-Aldrich), and sonicated for $10 \mathrm{~s}$. Samples were centrifuged at 13200 r.p.m. for $20 \mathrm{~min}$ at $4{ }^{\circ} \mathrm{C}$ and supernatants stored at $-80^{\circ} \mathrm{C}$. A BCA kit (Thermo Scientific, France) was used for protein determination. Levels of TNF $\alpha$ and IL-1 $\beta$ in these samples were measured using ELISA kits (Invitrogen, Thermo-scientific, France) according to the manufacturer's protocol.

Calcium imaging. Acute brain hemisphere slices from 9-month-old mice were incubated for $60 \mathrm{~min}$ at $37^{\circ} \mathrm{C}$ in ACSF containing $0.02 \%$ Pluronic F-127 and Fluo-4 AM ( $5 \mu \mathrm{M}$, Molecular Probes), a calcium indicator specifically loaded in astrocytes. ${ }^{58}$ In some experiments, astrocytes were also identified by their ability to take in SR101. For that, acute slices were incubated for $20 \mathrm{~min}$ at $34^{\circ} \mathrm{C}$ in ACSF solution containing $1 \mu \mathrm{M}$ SR101, washed and processed as above for Fluo-4 AM loading. Fluo-4 AM-loaded slices were further treated with different agents separately: BAPTA-AM $(25 \mu \mathrm{M})$ during $45 \mathrm{~min}$, and antagonists of phospholipase C (U73122, $5 \mu \mathrm{M}$, Tocris, Bristol, UK), IP3R (2-APB, $100 \mu \mathrm{M}$, Tocris), Ryanodine receptor (RyR) (dantrolene, $30 \mu \mathrm{M}$, Tocris), mGluR5 (MPEP $10 \mu \mathrm{M}$ and SIB1757 $50 \mu \mathrm{M}$, Tocris) and purinergic receptors (PPADS $100 \mu \mathrm{M}$ and suramin $100 \mu \mathrm{M}$, Tocris) during $30 \mathrm{~min}$. Then, slices were transferred on the stage of a two-photon microscope and $\mathrm{Ca}^{2+}$ measurements were carried out. Fluo-4 AM was excited at $910 \mathrm{~nm}$, using a pulsed Maitai (Spectra Physics, Evry, France) laser. Emitted fluorescence was detected using two non-descanned detectors, with a $525 / 50 \mathrm{~nm}$ filter. Acquisitions were carried out with a Leica $\times 25, N A=0.95$, water immersion objective (with a zoom $\times 1.5$ ) on a Leica SP5 MP microscope controlled by the Leica Acquisition Software. When SR101 was used, it was excited at $760 \mathrm{~nm}$ and the emitted fluorescence was detected using a $585 / 40 \mathrm{~nm}$ filter. Images were analyzed offline: the mean fluorescence intensity of astrocyte soma reflecting the resting $\mathrm{Ca}^{2+}$ level was measured with Image $\mathrm{J}$ software.

Determination of L-glutamate and GABA levels by commercial laser-induced fluorescence capillary electrophoresis. Extracellular levels of L-glutamate and GABA were determined from acute brain hemisphere slices of 9-month-old mice (two slices/tube/condition, in five mice per genotype) incubated in $1 \mathrm{ml}$ oxygenated ACSF as described. ${ }^{59}$ Slices were treated with HC blockers during $150 \mathrm{~min}$; samples of extracellular medium were collected, directly frozen in liquid nitrogen and stored at $-80^{\circ} \mathrm{C}$. Intracellular levels of L-glutamate and GABA in slices were also analyzed. Briefly, pooled slices were deproteinized by addition of cold trichloroacetic acid to a $5 \%$ final concentration. The suspension was centrifuged at $16800 \times \mathrm{g}$ for $10 \mathrm{~min}$; the trichloroacetic acid was extracted from the supernatant with water-saturated diethyl ether and stored at $-80^{\circ} \mathrm{C}$. Samples were analyzed with a commercial laser-induced fluorescence capillary electrophoresis (capillary electrophoresis: Beckman Coulter (Villepinte, France), P/ACE MDQ; laserinduced fluorescence: Picometrics (Labège, France), LIF-UV-02, $410 \mathrm{~nm} 20 \mathrm{~mW}$ ) as following: samples were processed for micellar commercial laser-induced fluorescence capillary electrophoresis and were fluorescently derivatized at RT for 
60 min with napthalene-2,3-dicarboxaldehyde before being analyzed by CE using a hydroxypropyl- $\beta$-cyclodextrin based chiral separation buffer. All electropherogram data were collected and analyzed using Karat 32 software v8.0 (Beckman Coulter). Further analysis was made using GraphPad Prism 4.03 software.

The extracellular and intracellular amounts of L-glutamate and GABA were normalized to the protein content determined from pooled slices using the BCA kit. The quantity of L-glutamate and GABA in the samples was determined from a standardized curve while peak identification was made by spiking the fraction with the amino acid. For accurate comparison between conditions, extracellular levels of L-glutamate (referred as [glut] ext) were normalized to total L-glutamate (intracellular+extracellular) (referred as [glut] $]_{\text {tot }}$ ) allowing to assess the released fraction of L-glutamate. $[\mathrm{GABA}]_{\text {ext }}$ was also normalized to $[\mathrm{GABA}]_{\text {tot- }}$.

Determination of ATP extracellular levels by bioluminescence. Extracellular levels of ATP were determined from acute brain hemisphere slices of 9-month-old mice (two slices/tube/condition, five mice per genotype) incubated in $1 \mathrm{ml}$ oxygenated ACSF. After equilibration, slices were treated or not with $\mathrm{HC}$ blockers during $30 \mathrm{~min}$ in the presence of an ectonucleotidase inhibitor, 6-N,N-diethyl- $\beta$ - $\gamma$-dibromomethylene-D-adenosine-5-triphosphate FPL 67156 (ARL 67156 trisodium salt, Tocris) to inhibit ATP hydrolysis. Then, samples of extracellular medium were collected and extracellular ATP was directly measured using the luciferin-luciferase bioluminescent assay (ATPLite kit, Perkin Elmer, Waltham, MA, USA). Each condition was run in triplicate. Luminescence was measured using a luminometer (Berthold Technologies, Thoiry, France) according to the manufacturer's instructions. The extracellular ATP was normalized to the protein content determined from pooled brain slices by BCA kit (as above).

Immunohistochemical stainings. Cryostat sections $(15 \mu \mathrm{m})$ prepared as previously described ${ }^{9}$ were fixed 30 min at RT with $4 \%$ paraformaldehyde, washed in PBS, treated 10 min with $70 \%$ formic acid (when mouse anti-A $\beta$ clone $4 \mathrm{G} 8$ wad used) and preincubated in PBS containing $0.2 \%$ gelatin and $0.25 \%$ Triton-X100 (PBS ${ }^{* *}$ ) for $30 \mathrm{~min}$. Sections were then processed for immunostaining by overnight incubation at $4{ }^{\circ} \mathrm{C}$ with primary antibodies including rabbit anti-A $\beta(1: 1000$, Life Technologies) and mouse anti-GFAP (1:500, Sigma-Aldrich) or mouse anti-A $\beta$ (clone 4G8, 1:500) and rabbit anti-RTN3 (R458, 1:1000) diluted in PBS**, washed in PBS** and incubated in secondary goat anti-rabbit and anti-mouse $\lg$ G antibodies conjugated with different Alexa FluoR (Molecular Probes) diluted 1:2000 in PBS**. Sections were washed, mounted in Fluoromount and examined with a confocal microscope.

Quantification of RTN3 immunoreactive dystrophic neurites. RTN3 immunoreactive dystrophic neurites (RIDNs) were quantified as previously described with slight modifications: ${ }^{60}$ stacks of 30 consecutive optical sections $(0.5 \mu \mathrm{m}$ each) were captured with a $\times 40$ objective and $Z$ maximal projections reconstructed with the Leica software. For each mouse (four age-matched mice per genotype were used), six brain sections every $120 \mu \mathrm{m}$ were stained and quantified. In each brain section, four maximal projection images were captured randomly in the cortex and hippocampus. Image J Software was used to quantify the area of RIDNs at the level of $A \beta$ plaques. Typically, the signals of RIDNs were bright, while cell staining by RTN3 antibodies was dim. RIDNs contained within $A \beta$ plaque areas were selected for quantification. Percentage of RIDNs area was calculated by dividing the total RIDNs area by the total area occupied by $A \beta$ plaques in each mouse.

Detection of mitochondrial superoxide in acute brain slices. Living brain hemisphere slices from 9-month-old mice were incubated with MitoSOX Red, a mitochondrial superoxide indicator (Life Technologies), $5 \mu \mathrm{M}$ in ACSF for $10 \mathrm{~min}$. Slices were then fixed with $4 \%$ paraformaldehyde at $4{ }^{\circ} \mathrm{C}$ for $1 \mathrm{~h}$. After washing and permeabilization in $\mathrm{PBS}^{*}$, slices were further incubated with TO-PRO-3 lodide (diluted in PBS* 1:2000, Life Technologies) at RT for $10 \mathrm{~min}$, rinsed and mounted onto slides with fluoromount. The slices were examined using a Leica SP5 confocal microscope with a $\times 40$ objective. Stacks of 22 consecutive confocal images taken at $0.5-\mu \mathrm{m}$ intervals were acquired sequentially with two lasers (561 nm for MitoSOX and $647 \mathrm{~nm}$ for TO-PRO). All parameters were held constant for all the sections. Four images covering the pyramidal layer visualized with TO-PRO nuclear staining in CA1 hippocampal formation were captured for each mouse (three age-matched mice per genotype). Image J Software was used to quantify the mean fluorescence intensity in the pyramidal cell layer.

Statistical analysis. Values are presented as mean \pm S.E.M.; $n$ corresponding to the number of independent experiments. Statistical analysis was performed on raw data with Graphpad software using one-way analysis of variance followed by Dunnett's test or via a two-tailed Student's $t$-test. The level of significance was set at $P<0.05$. Graphics were prepared using GraphPad prism (Northampton, MA, USA).

\section{Conflict of Interest}

The authors declare no conflict of interest.

Acknowledgements. We thank E Amigou and J Lelovski for technical help, $\mathrm{J}$ Teillon for confocal image analysis training, the animal facility staff and Prof $R$ Yan for the gift of anti-RTN3 antibodies. C YI was supported by FRM. This study was funded by LECMA, CRPCEN, MINECO/FEDER (Grant SAF2013-45084- R) and CIBERNED (Grant PRY-15-404).

\section{Author contributions}

AK wrote the manuscript; $C Y, A K$ and $C G$ designed the research; $C Y, X M, P E, S M$ and IM performed the research; $\mathrm{CY}$ analyzed the data.

1. Selkoe DJ. Cell biology of the amyloid beta-protein precursor and the mechanism of Alzheimer's disease. Annu Rev Cell Biol 1994; 10: 373-403.

2. Sofroniew MV, Vinters HV. Astrocytes: biology and pathology. Acta Neuropathol 2010; 119: 7-35.

3. Giaume C, Kirchhoff F, Matute C, Reichenbach A, Verkhratsky A. Glia: the fulcrum of brain diseases. Cell Death Differ 2007; 14: 1324-1335.

4. Verkhratsky A, Olabarria M, Noristani HN, Yeh CY, Rodriguez JJ. Astrocytes in Alzheimer's disease. Neurotherapeutics 7: 399-412.

5. Parpura V, Heneka MT, Montana V, Oliet SH, Schousboe A, Haydon PG et al. Glial cells in (patho)physiology. J Neurochem 2012; 121: 4-27.

6. Pekny M, Pekna M, Messing A, Steinhauser C, Lee JM, Parpura V et al. Astrocytes: a central element in neurological diseases. Acta Neuropathol 2016; 131: 323-345.

7. Nagy Jl, Li W, Hertzberg EL, Marotta CA. Elevated connexin43 immunoreactivity at sites of amyloid plaques in Alzheimer's disease. Brain Res 1996; 717: 173-178.

8. Koulakoff A, Mei X, Orellana JA, Saez JC, Giaume C. Glial connexin expression and function in the context of Alzheimer's disease. Biochim Biophys Acta 2012; 1818: 2048-2057.

9. Mei X, Ezan P, Giaume C, Koulakoff A. Astroglial connexin immunoreactivity is specifically altered at beta-amyloid plaques in beta-amyloid precursor protein/presenilin1 mice. Neuroscience 2010; 171: 92-105.

10. Giaume C, Koulakoff A, Roux L, Holcman D, Rouach N. Astroglial networks: a step further in neuroglial and gliovascular interactions. Nat Rev Neurosci 2010; 11: 87-99.

11. Rouach N, Koulakoff A, Abudara V, Willecke K, Giaume C. Astroglial metabolic networks sustain hippocampal synaptic transmission. Science 2008; 322: 1551-1555.

12. Cruz NF, Ball KK, Dienel GA. Astrocytic gap junctional communication is reduced in amyloidbeta-treated cultured astrocytes, but not in Alzheimer's disease transgenic mice. ASN Neuro 2010; 2: e00041.

13. Peters O, Schipke CG, Philipps A, Haas B, Pannasch U, Wang LP et al. Astrocyte function is modified by Alzheimer's disease-like pathology in aged mice. J Alzheimers Dis 2009; 18: 177-189.

14. Giaume C, Leybaert L, Naus CC, Saez JC. Connexin and pannexin hemichannels in brain glial cells: properties, pharmacology, and roles. Front Pharmacol 2013; 4: 88.

15. MacVicar BA, Thompson RJ. Non-junction functions of pannexin-1 channels. Trends Neurosci 2010; 33: 93-102.

16. Orellana JA, von Bernhardi R, Giaume C, Saez JC. Glial hemichannels and their involvement in aging and neurodegenerative diseases. Rev Neurosci 2012; 23: 163-177.

17. Davidson JO, Green CR, Bennet L, Nicholson LF, Danesh-Meyer H, O'Carroll SJ et al. A key role for connexin hemichannels in spreading ischemic brain injury. Curr Drug Targets 2013; 14: $36-46$.

18. Chen G, Park CK, Xie RG, Berta T, Nedergaard M, Ji RR. Connexin-43 induces chemokine release from spinal cord astrocytes to maintain late-phase neuropathic pain in mice. Brain 2014; 137(Pt 8): 2193-2209.

19. Retamal MA, Froger N, Palacios-Prado N, Ezan P, Saez PJ, Saez JC et al. Cx43 hemichannels and gap junction channels in astrocytes are regulated oppositely by proinflammatory cytokines released from activated microglia. J Neurosci 2007; 27: 13781-13792.

20. Karpuk N, Burkovetskaya M, Fritz T, Angle A, Kielian T. Neuroinflammation leads to regiondependent alterations in astrocyte gap junction communication and hemichannel activity. J Neurosci 2011; 31: 414-425.

21. Orellana JA, Shoji KF, Abudara V, Ezan P, Amigou E, Saez PJ et al. Amyloid beta-induced death in neurons involves glial and neuronal hemichannels. J Neurosci 2011; 31: 4962-4977.

22. Abudara V, Roux L, Dallerac G, Matias I, Dulong J, Mothet JP et al. Activated microglia impairs neuroglial interaction by opening $\mathrm{C} \times 43$ hemichannels in hippocampal astrocytes. Glia 2015; 63: 795-811. 
23. Delekate A, Fuchtemeier M, Schumacher T, Ulbrich C, Foddis M, Petzold GC. Metabotropic P2Y1 receptor signalling mediates astrocytic hyperactivity in vivo in an Alzheimer's disease mouse model. Nat Commun 2014; 5: 5422.

24. Jankowsky JL, Slunt HH, Ratovitski T, Jenkins NA, Copeland NG, Borchelt DR. Coexpression of multiple transgenes in mouse CNS: a comparison of strategies. Biomol Eng 2001; 17: 157-165.

25. Giaume C, Orellana JA, Abudara V, Saez JC. Connexin-based channels in astrocytes: how to study their properties. Methods Mol Biol 2012; 814: 283-303.

26. Kim HS, Suh YH. Minocycline and neurodegenerative diseases. Behav Brain Res 2009; 196 168-179.

27. De Vuyst E, Wang N, Decrock E, De Bock M, Vinken M, Van Moorhem $\mathrm{M}$ et al. $\mathrm{Ca}(2+)$ regulation of connexin 43 hemichannels in $\mathrm{C} 6$ glioma and glial cells. Cell Calcium 2009; 46 : 176-187.

28. Kuchibhotla KV, Lattarulo CR, Hyman BT, Bacskai BJ. Synchronous hyperactivity and intercellular calcium waves in astrocytes in Alzheimer mice. Science 2009; 323: 1211-1215.

29. Ma T, Du X, Pick JE, Sui G, Brownlee M, Klann E. Glucagon-like peptide-1 cleavage produc GLP-1(9-36) amide rescues synaptic plasticity and memory deficits in Alzheimer's disease model mice. J Neurosci 2012; 32: 13701-13708.

30. Meyer-Luehmann M, Spires-Jones TL, Prada C, Garcia-Alloza M, de Calignon A, Rozkalne $\mathrm{A}$ et al. Rapid appearance and local toxicity of amyloid-beta plaques in a mouse model of Alzheimer's disease. Nature 2008; 451: 720-724.

31. Hu X, Shi $Q$, Zhou X, He W, Yi H, Yin X et al. Transgenic mice overexpressing reticulon 3 develop neuritic abnormalities. EMBO J 2007; 26: 2755-2767.

32. Contreras JE, Sanchez HA, Eugenin EA, Speidel D, Theis M, Willecke K et al. Metabolic inhibition induces opening of unapposed connexin 43 gap junction hemichannels and reduces gap junctional communication in cortical astrocytes in culture. Proc Natl Acad Sci USA 2002; 99: 495-500.

33. Froger N, Orellana JA, Calvo CF, Amigou E, Kozoriz MG, Naus CC et al. Inhibition of cytokine-induced connexin43 hemichannel activity in astrocytes is neuroprotective. Mol Cell Neurosci 2010; 45: 37-46.

34. Iglesias R, Dahl G, Qiu F, Spray DC, Scemes E. Pannexin 1: the molecular substrate of astrocyte "hemichannels". J Neurosci 2009; 29: 7092-7097.

35. Busche MA, Eichhoff $G$, Adelsberger $\mathrm{H}$, Abramowski D, Wiederhold KH, Haass $\mathrm{C}$ et al. Clusters of hyperactive neurons near amyloid plaques in a mouse model of Alzheimer's disease. Science 2008; 321: 1686-1689.

36. Silverman WR, de Rivero Vaccari JP, Locovei S, Qiu F, Carlsson SK, Scemes E et al. The pannexin 1 channel activates the inflammasome in neurons and astrocytes. $J$ Biol Chem 2009; 284: 18143-18151.

37. Parvathenani LK, Tertyshnikova S, Greco CR, Roberts SB, Robertson B, Posmantur R. $\mathrm{P} 2 \mathrm{X} 7$ mediates superoxide production in primary microglia and is up-regulated in a transgenic mouse model of Alzheimer's disease. J Biol Chem 2003; 278: 13309-13317.

38. Alberdi E, Wyssenbach A, Alberdi M, Sanchez-Gomez MV, Cavaliere F, Rodriguez JJ et al. $\mathrm{Ca}(2+)$-dependent endoplasmic reticulum stress correlates with astrogliosis in oligomeric amyloid beta-treated astrocytes and in a model of Alzheimer's disease. Aging Cell 2013; 12 : 292-302.

39. Grolla AA, Fakhfouri G, Balzaretti G, Marcello E, Gardoni F, Canonico PL et al. Abeta leads to $\mathrm{Ca}(2)(+)$ signaling alterations and transcriptional changes in glial cells. Neurobiol Aging 2013; 34: 511-522.

40. De Bock M, Wang N, Bol M, Decrock $E$, Ponsaerts $R$, Bultynck $G$ et al. Connexin 43 hemichannels contribute to cytoplasmic $\mathrm{Ca} 2+$ oscillations by providing a bimodal Ca2+-dependent Ca2+ entry pathway. J Biol Chem 2012; 287: 12250-12266.
41. Ye ZC, Wyeth MS, Baltan-Tekkok S, Ransom BR. Functional hemichannels in astrocytes: a novel mechanism of glutamate release. J Neurosci 2003; 23: 3588-3596.

42. Stridh MH, Tranberg M, Weber SG, Blomstrand F, Sandberg M. Stimulated efflux of amino acids and glutathione from cultured hippocampal slices by omission of extracellular calcium: likely involvement of connexin hemichannels. J Biol Chem 2008; 283: 10347-10356.

43. Stout CE, Costantin JL, Naus CC, Charles AC. Intercellular calcium signaling in astrocytes via ATP release through connexin hemichannels. J Biol Chem 2002; 277: 10482-10488.

44. Kang J, Kang N, Lovatt D, Torres A, Zhao Z, Lin J et al. Connexin 43 hemichannels are permeable to ATP. J Neurosci 2008; 28: 4702-4711.

45. Jo S, Yarishkin O, Hwang YJ, Chun YE, Park M, Woo DH et al. GABA from reactive astrocytes impairs memory in mouse models of Alzheimer's disease. Nat Med 2014; 20 886-896.

46. Talantova M, Sanz-Blasco S, Zhang X, Xia P, Akhtar MW, Okamoto S et al. Abeta induces astrocytic glutamate release, extrasynaptic NMDA receptor activation, and synaptic loss. Proc Natl Acad Sci USA 2013; 110: E2518-E2527.

47. Kuchibhotla KV, Goldman ST, Lattarulo CR, Wu HY, Hyman BT, Bacskai BJ. Abeta plaques lead to aberrant regulation of calcium homeostasis in vivo resulting in structural and functional disruption of neuronal networks. Neuron 2008; 59: 214-225.

48. Lin MT, Beal MF. Mitochondrial dysfunction and oxidative stress in neurodegenerative diseases. Nature 2006; 443: 787-795.

49. Xie H, Hou S, Jiang J, Sekutowicz M, Kelly J, Bacskai BJ. Rapid cell death is preceded by amyloid plaque-mediated oxidative stress. Proc Natl Acad Sci USA 2013; 110: 7904-7909.

50. Pelegrin $P$, Surprenant $A$. The $P 2 X(7)$ receptor-pannexin connection to dye uptake and IL-1beta release. Purinergic Signal 2009; 5: 129-137.

51. Erb L, Cao C, Ajit D, Weisman GA. P2Y receptors in Alzheimer's disease. Biol Cell 2015 107: 1-21.

52. Fujita T, Tozaki-Saitoh H, Inoue K. P2Y1 receptor signaling enhances neuroprotection by astrocytes against oxidative stress via IL-6 release in hippocampal cultures. Glia 2009; 57 244-257.

53. Jimenez S, Torres M, Vizuete M, Sanchez-Varo R, Sanchez-Mejias E, Trujillo-Estrada L et al. Age-dependent accumulation of soluble amyloid beta (Abeta) oligomers reverses the neuroprotective effect of soluble amyloid precursor protein-alpha (sAPP(alpha)) by modulating phosphatidylinositol 3-kinase (PI3K)/Akt-GSK-3beta pathway in Alzheimer mouse model. J Biol Chem 2011; 286: 18414-18425.

54. Delarasse C, Auger R, Gonnord P, Fontaine B, Kanellopoulos JM. The purinergic receptor $\mathrm{P} 2 \mathrm{X7}$ triggers alpha-secretase-dependent processing of the amyloid precursor protein. $\mathrm{J}$ Biol Chem 2011; 286: 2596-2606.

55. Durand D, Carniglia L, Beauquis J, Caruso C, Saravia F, Lasaga M. Astroglial mGlu3 receptors promote alpha-secretase-mediated amyloid precursor protein cleavage. Neuropharmacology 2014; 79: 180-189.

56. Cotrina ML, Gao Q, Lin JH, Nedergaard M. Expression and function of astrocytic gap junctions in aging. Brain Res 2001; 901: 55-61.

57. Nimmerjahn A, Kirchhoff F, Kerr JN, Helmchen F. Sulforhodamine 101 as a specific marke of astroglia in the neocortex in vivo. Nat Methods 2004; 1: 31-37.

58. Hirase H, Qian L, Bartho P, Buzsaki G. Calcium dynamics of cortical astrocytic networks in vivo. PLoS Biol 2004; 2: E96.

59. Fossat P, Turpin FR, Sacchi S, Dulong J, Shi T, Rivet JM et al. Glial D-serine gates NMDA receptors at excitatory synapses in prefrontal cortex. Cereb Cortex 2012; 22 $595-606$

60. Shi Q, Hu X, Prior M, Yan R. The occurrence of aging-dependent reticulon 3 immunoreactive dystrophic neurites decreases cognitive function. J Neurosci 2009; 29: 5108-5115.

Supplementary Information accompanies this paper on Cell Death and Differentiation website (http://www.nature.com/cdd) 